\title{
A SEXUALIDADE DA MULHER COM CÂNCER DE MAMA: ANÁLISE DA PRODUÇÃO CIENTÍFICA DE ENFERMAGEM
}

\author{
Simone Mara de Araújo Ferreira', Marislei Sanches Panobianco², Thaís de Oliveira Gozzo³, Ana Maria de \\ Almeida ${ }^{4}$
}

\footnotetext{
${ }^{1}$ Mestranda do Programa de Pós-Graduação Enfermagem em Saúde Pública da Escola de Enfermagem de Ribeirão Preto (EERP) da Universidade de São Paulo (USP). Ribeirão Preto, São Paulo, Brasil. E-mail: sisicg@yahoo.com.br

${ }^{2}$ Doutora em Enfermagem. Professora do Departamento de Enfermagem Materno-Infantil e Saúde Pública da EERP/USP. Ribeirão Preto, São Paulo, Brasil. E-mail: marislei@eerp.usp.br

${ }^{3}$ Doutora em Enfermagem. Professora do Departamento de Enfermagem Materno-Infantil e Saúde Pública da EERP/USP. Ribeirão Preto, São Paulo, Brasil. E-mail: thaisog@eerp.usp.br

${ }^{4}$ Doutora em Enfermagem. Professora Associado do Departamento de Enfermagem Materno-Infantil e Saúde Pública da Brasil. Ribeirão Preto, São Paulo, Brasil. E-mail: amalmeid@eerp.usp.br
}

RESUMO: Revisão integrativa que objetivou analisar o conhecimento produzido pela enfermagem brasileira sobre a sexualidade de mulheres com câncer de mama, visando a melhoria do cuidado de enfermagem. Foi utilizada a busca simultânea por palavras, em todas as bases de dados indexadas na Biblioteca Virtual da Saúde. Incluíram-se 10 artigos publicados a partir do ano 2000, cuja autoria fosse atribuída ao profissional enfermeiro. Os resultados mostraram que a sexualidade das mulheres, muitas vezes, está restrita à prática sexual, e apenas alguns relatos mostram a sexualidade como algo mais abrangente. As mulheres acometidas pelo câncer de mama apresentam comprometimento no exercício da sexualidade, e o apoio do companheiro auxilia no enfrentamento, sendo percebido como muito significativo em todas as etapas da doença. A análise dos estudos evidencia uma assistência de enfermagem que não contempla esse aspecto do cuidado, necessitando de reestruturação. Essa assistência deve ser estendida aos parceiros e deve ultrapassar a dimensão biológica.

DESCRITORES: Neoplasias da mama. Sexualidade. Enfermagem.

\section{SEXUALITY OF WOMEN WITH BREAST CANCER: ANALYSIS OF SCIENTIFIC PRODUCTION IN NURSING}

\begin{abstract}
Integrative review aimed at analyzing the knowledge produced by Brazilian nursing concerning the sexuality of women with breast cancer, with a view to improving the quality of care delivery. A simultaneous search by word was performed in all the databases listed in the Online Health Library. Ten articles were included, published as from the year 2000, whose authors were nursing professionals. The results revealed that women's sexuality is often limited to the sexual practice and that only some reports show sexuality as something broader. Women affected by breast cancer have their sexuality compromised and the support provided by their partners helps them with coping and is considered very significant in all stages of the disease. The analysis of the studies reveals that nursing care does not cover this aspect of care and needs to be restructured. This care should be extended to the partners and go beyond the biological dimension.
\end{abstract}

DESCRIPTORS: Breast neoplasms. Sexuality. Nursing.

\section{SEXUALIDAD DE LA MUJER CON CÁNCER DE MAMA: ANÁLISIS DE LA PRODUCCIÓN CIENTÍFICA DE ENFERMERÍA}

RESUMEN: Revisión integrativa que tuvo por como objetivo analizar el conocimiento producido por la enfermería brasileña sobre la sexualidad de mujeres con cáncer de mama, con la finalidad de obtener subsidios para ofrecer una asistencia de calidad. Fue utilizada una busca simultánea por palabras, en todas las bases de datos indexadas en la BVS. Se incluyeron 10 artículos publicados a partir del año 2000, en cuya autoría constaban enfermeros. Los resultados mostraron que la sexualidad de las mujeres muchas veces está restricta a la práctica sexual y apenas unos relatos muestran la sexualidad como algo más integral. Las mujeres afectadas por cáncer de mama presentan dificultad en el ejercicio de la sexualidad y el apoyo del compañero ayuda a hacer ese enfrentamiento, siendo percibido como de extrema significancia en todas las etapas de la enfermedad. El análisis de los resultados evidencia una asistencia de Enfermería que no contempla este aspecto del cuidado, evidenciándose las necesidad de una reestructuración. Esa asistencia debe ser extendida a los compañeros y debe ultrapasar la dimensión biológica.

DESCRIPTORES: Neoplasias de mama. Sexualidad. Enfermería. 


\section{INTRODUÇÃO}

O diagnóstico do câncer de mama, assim como todo o percurso da doença, é permeado por muitas inquietações relacionadas à morte, às mutilações e à dor, constituindo-se num período marcado por muita angústia, sofrimento e ansiedade. ${ }^{1}$

O tratamento se dá, principalmente, através de cirurgia, radioterapia e quimioterapia, e cerca de $50 \%$ das mulheres sobreviverão por pelo menos 15 anos. ${ }^{2}$ Sobreviver a esse acontecimento significa ajustar-se à nova condição, permeada por sequelas de âmbito físico e psicossocial, com repercussões negativas na sexualidade e na função sexual.

A mutilação decorrente do procedimento cirúrgico causa inibição, durante a relação sexual, e gera sentimentos de vergonha, angústia e constrangimento. ${ }^{3}$ A mastectomia pode ser descrita como um assalto dramático no corpo, situação que, sem dúvida, afeta a concepção da mulher enquanto ser sexual. ${ }^{4}$

Os efeitos secundários da quimioterapia tais como fadiga, alopecia, constipação, náuseas, vômitos e ganho de peso, entre outros, contribuem para alterar a função sexual, uma vez que diminuem a libido feminina e a capacidade de a mulher engajar-se na atividade sexual. ${ }^{5}$

Poucos profissionais de saúde valorizam os sentimentos de baixa autoestima e os aspectos relacionados à sexualidade da mulher com câncer de mama. ${ }^{6}$ Situação semelhante acontece na prática de enfermagem, onde a sexualidade é tratada como uma questão invisível e, ao mesmo tempo, oculta. É como se ela não existisse, fosse ignorada e, quando aparece, por motivos pouco conhecidos, não é explorada.?

Considerando que os tratamentos do câncer de mama podem repercutir na sexualidade da mulher, torna-se necessária uma mudança na prática assistencial. Destaca-se, assim, a necessidade de um olhar mais ampliado a essa problemática de modo que as vivências, os significados e as experiências vividas por essas mulheres possam ser contempladas nas práticas assistenciais de enfermagem.

O enfermeiro precisa identificar os problemas decorrentes do processo de adoecimento e implementar cuidados que visem à promoção da saúde sexual das pacientes. ${ }^{8}$ Entretanto, observase que aspectos relacionados à sexualidade são pouco explorados na prática clinica, bem como, apenas mais recentemente, passou a ser objeto de pesquisa pela enfermagem.
Considerando que esses cuidados e intervenções precisam ser baseados em evidências científicas, permitindo uma prática fundamentada no conhecimento científico produzido, o presente estudo teve como objetivo analisar o conhecimento produzido pela enfermagem brasileira sobre a sexualidade de mulheres com câncer de mama, visando a melhoria do cuidado de enfermagem.

\section{MÉTODO}

O método de pesquisa utilizado foi a revisão integrativa da literatura que, por meio de uma análise crítica dos estudos, permite a síntese geral a respeito de uma área de conhecimento, além de apontar lacunas. Trata-se de um método de condensação de pesquisas anteriores, em que conclusões são estabelecidas proporcionando um entendimento mais abrangente do fenômeno em estudo. ${ }^{9}$

Para guiar o presente estudo, formularam-se as seguintes questões: a sexualidade tem sido objeto de produção de conhecimento na enfermagem? Qual o conhecimento produzido pela Enfermagem brasileira acerca da sexualidade de mulheres com câncer de mama?

O levantamento foi realizado entre os meses de fevereiro e março de 2010 e utilizaram-se as seguintes palavras-chave relacionadas ao tema: câncer de mama (sinônimo do descritor em português neoplasias da mama), sexualidade e enfermagem. Para ampliar a busca de artigos, foi feita a combinação entre as palavras.

Os critérios de inclusão das publicações selecionadas para a presente revisão foram: produção brasileira; artigos cuja autoria incluísse o enfermeiro; publicação a partir do ano 2000; e artigos disponibilizados na íntegra. Foram excluídos os artigos que tratavam outros tipos de câncer que não o de mama, produções de outras categorias profissionais, dissertações, teses e livros ou capítulo de livro.

A fonte de dados bibliográficos foi a Biblioteca Virtual em Saúde (BVS) com acesso via internet. Foi utilizada a busca simultânea por palavras, em todas as bases de dados indexadas na BVS (BDENF - Base de Dados de Enfermagem; LILACS - Literatura Latino-Americana e do Caribe em Ciências da Saúde; MEDLINE - Literature Analysis and Retrieval System on-line; Coleciona SUS - Coleção Nacional das Fontes de Informações do SUS; MS - Acervo da Biblioteca do Ministério da Saúde; e WHOLIS - Sistema de Informação da Biblioteca da OMS). 
No quadro 1 estão apresentados os números

conforme palavras utilizadas.

de artigos encontrados em cada base de dados,

Quadro 1 - Demonstrativo da localização dos artigos nas bases de dados, conforme palavras utilizadas

\begin{tabular}{|l|c|c|c|}
\hline \multirow{2}{*}{ Bases de dados da BVS } & \multicolumn{3}{|c|}{ Palavras utilizadas na busca } \\
\cline { 2 - 4 } & Câncer de mama & Sexualidade & Câncer de mama e sexualidade \\
\hline BDENF & 118 & 254 & 5 \\
\hline LILACS & 4309 & 2280 & 17 \\
\hline MEDLINE & - & 3006 & - \\
\hline MS & 39 & 188 & - \\
\hline OPAS & 55 & 24 & - \\
\hline WHOLIS & 49 & 18 & - \\
\hline Artigos & 8 & 5 & - \\
\hline Teses & 36 & 61 & - \\
\hline Coleciona SUS & 28 & 28 & 3 \\
\hline Publicações periódicas & 17 & 57 & \\
\hline
\end{tabular}

Após a leitura criteriosa do título e resumo, para verificar a adequação com a questão norteadora e critérios de inclusão, a amostra resultou num total de 10 artigos, localizados nas bases de dados BDENF e LILACS. Nas demais bases de dados da BVS, não foram encontrados artigos que respondessem aos critérios de inclusão exigidos neste estudo. Vale destacar que alguns estavam indexados em mais de uma base de dados.

Os artigos incluídos na revisão foram lidos na íntegra, categorizados e avaliados com o auxílio de um instrumento de coleta de dados, previamente elaborado, ${ }^{9}$ que possui os seguintes itens: identificação, instituição-sede do estudo, tipo de revista científica, características metodológicas do estudo e avaliação do rigor metodológico. Os mesmos foram analisados, e a síntese foi realizada de maneira descritiva por meio de categorias temáticas, utilizando-se a técnica de Análise de Conteúdo. Esse processo utiliza grande raciocínio indutivo, pelo qual temas e categorias emergem dos dados por meio de um exame criterioso e por constantes comparações. ${ }^{10}$

\section{RESULTADOS}

De acordo com o local em que foram desenvolvidos, três artigos tiveram como cenários de estudo serviços especializados e vinculados a universidades, seis foram desenvolvidos em hospitais e um em um instituto de prevenção.

Com relação ao periódico, os estudos foram publicados em nove periódicos diferentes, sendo sete de enfermagem e dois interdisciplinares.

Em relação aos sujeitos de estudo, nove artigos tiveram como amostra mulheres mastectomizadas. O número de participantes variou de cinco a 24. Apenas um estudo teve como sujeitos de pesquisa os parceiros dessas mulheres. A identificação e as características metodológicas dos 10 artigos selecionados estão apresentadas no quadro 2.

\section{Quadro 2 - Caracterização dos artigos selecionados}

\begin{tabular}{|l|l|l|l|}
\hline Artigos & Tipo de estudo & Objetivos & Amostra \\
\hline $\begin{array}{l}\text { Rodrigues, } \\
\text { Silva, } \\
\text { Lopes }^{11}\end{array}$ & $\begin{array}{l}\text { Estudo qualitativo } \\
\text { de caráter descriti- } \\
\text { vo - nível VI }\end{array}$ & $\begin{array}{l}\text { Analisar a percepção da mulher mas- } \\
\text { tectomizada acerca de sua sexualidade, } \\
\text { enfatizando as modificações percebidas e } \\
\text { a participação do companheiro. }\end{array}$ & $\begin{array}{l}21 \text { mulheres, com câncer de mama, } \\
\text { mastectomia no mínimo há três me- } \\
\text { ses, acompanhamento no Instituto } \\
\text { de Prevenção do Câncer do Ceará } \\
\text { e casadas ou com companheiro } \\
\text { fixo. }\end{array}$ \\
\hline $\begin{array}{l}\text { Ferreira, } \\
\text { Franco, } \\
\text { Queiroz }\end{array}$ & $\begin{array}{l}\text { Abordagem qualita- } \\
\text { tiva - nível VI }\end{array}$ & $\begin{array}{l}\text { Compreender o significado da mastec- } \\
\text { tomia para mulheres no pós-operatório } \\
\text { por câncer de mama, em seguimento no no } \\
\text { ambulatório de mastologia e setores de } \\
\text { rádio e quimioterapia. }\end{array}$ & $\begin{array}{l}\text { 24 mulheres que realizaram cirurgia } \\
\text { para câncer de mama; em segui- } \\
\text { mento no ambulatório de mastolo- } \\
\text { gia e em tratamentos complementa- } \\
\text { res de rádio e quimioterapia. }\end{array}$ \\
\hline
\end{tabular}




\begin{tabular}{|c|c|c|c|}
\hline Artigos & Tipo de estudo & Objetivos & Amostra \\
\hline $\begin{array}{l}\text { Souto, } \\
\text { Souza }^{13}\end{array}$ & $\begin{array}{l}\text { Qualitativo fenome- } \\
\text { nológico - nível VI }\end{array}$ & $\begin{array}{l}\text { Desvelar o sentido das expressões de se- } \\
\text { xualidade da mulher submetida à mastec- } \\
\text { tomia radical, em decorrência do câncer } \\
\text { de mama. }\end{array}$ & $\begin{array}{l}15 \text { mulheres com câncer de mama } \\
\text { submetidas à mastectomia radical, } \\
\text { independente do período pós- } \\
\text { operatório. }\end{array}$ \\
\hline $\begin{array}{l}\text { Biffi, } \\
\text { Mamede }^{14}\end{array}$ & $\begin{array}{l}\text { Abordagem qualita- } \\
\text { tiva - nível VI }\end{array}$ & $\begin{array}{l}\text { Identificar o tipo de suporte social, ofere- } \\
\text { cido pelos parceiros sexuais de mulheres } \\
\text { com câncer de mama, e como este apoio } \\
\text { é percebido por eles. }\end{array}$ & $\begin{array}{l}\text { Nove parceiros de mulheres } \\
\text { acometidas por câncer de mama, } \\
\text { participantes do Núcleo de Ensino, } \\
\text { Pesquisa e Assistência na Rea- } \\
\text { bilitação de Mastectomizadas da } \\
\text { EERP/USP. }\end{array}$ \\
\hline $\begin{array}{l}\text { Barbosa, } \\
\text { Ximenes, } \\
\text { Pinheiro }^{15}\end{array}$ & $\begin{array}{l}\text { Abordagem qualita- } \\
\text { tiva - nível VI }\end{array}$ & $\begin{array}{l}\text { Compreender a influência da mastectomia } \\
\text { no desempenho de papéis da mulher; Co- } \\
\text { nhecer os sentimentos da mulher mastec- } \\
\text { tomizada frente à descoberta do câncer } \\
\text { de mama e da mastectomia; Identificar os } \\
\text { papéis desempenhados pela mulher antes } \\
\text { e depois da mastectomia; e Verificar o su- } \\
\text { porte de apoio que interfere no desempe- } \\
\text { nho de papéis da mulher mastectomizada. }\end{array}$ & $\begin{array}{l}\text { Sete mulheres mastectomizadas } \\
\text { que frequentavam o Grupo de } \\
\text { Autoajuda, Ensino, Pesquisa e } \\
\text { Assistência à mulher Mastectomi- } \\
\text { zada (GEPAM) da Universidade do } \\
\text { Ceará. }\end{array}$ \\
\hline $\begin{array}{l}\text { Caetano, } \\
\text { Soares }^{16}\end{array}$ & $\begin{array}{l}\text { Abordagem qualita- } \\
\text { tiva - nível VI }\end{array}$ & $\begin{array}{l}\text { Compreender a repercussão da mastecto- } \\
\text { mia sobre a mulher, com base na Teoria de } \\
\text { Adaptação de Roy, no modo autoconceito. }\end{array}$ & $\begin{array}{l}10 \text { mulheres com câncer de mama, } \\
\text { atendidas numa unidade de refe- } \\
\text { rência na região Norte do Estado do } \\
\text { Ceará, no setor de oncologia. }\end{array}$ \\
\hline $\begin{array}{l}\text { Azevedo, } \\
\text { Lopes }^{17}\end{array}$ & $\begin{array}{l}\text { Estudo qualitativo } \\
\text { com abordagem } \\
\text { fenomenológica - } \\
\text { nível VI }\end{array}$ & $\begin{array}{l}\text { Compreender o impacto cirúrgico na } \\
\text { percepção do próprio corpo e na relação } \\
\text { deste com as demais pessoas. }\end{array}$ & $\begin{array}{l}\text { Cinco mulheres submetidas à mas- } \\
\text { tectomia radical. }\end{array}$ \\
\hline $\begin{array}{l}\text { Gonçalves, } \\
\text { Arrais, } \\
\text { Fernandes }^{18}\end{array}$ & $\begin{array}{l}\text { Abordagem qualita- } \\
\text { tiva - nível VI }\end{array}$ & $\begin{array}{l}\text { Identificar as reações das mulheres frente } \\
\text { ao diagnóstico de câncer de mama, bem } \\
\text { como as alterações ocorridas no cotidiano } \\
\text { dessas mulheres após a mastectomia, } \\
\text { descrevendo os mecanismos de enfrenta- } \\
\text { mento para a superação das dificuldades } \\
\text { decorrentes da cirurgia. }\end{array}$ & $\begin{array}{l}15 \text { mulheres comum a cinco anos } \\
\text { de mastectomia e com parceiros } \\
\text { fixos. } \\
\text { Mulheres que participam das reu- } \\
\text { niões do GEPAM do Departamento } \\
\text { de Enfermagem da Universidade } \\
\text { Federal do Ceará. }\end{array}$ \\
\hline $\begin{array}{l}\text { Madeira, } \\
\text { Almeida, } \\
\text { Jesus }^{19}\end{array}$ & $\begin{array}{l}\text { Qualitativo fenome- } \\
\text { nológico - nível VI }\end{array}$ & $\begin{array}{l}\text { Compreender o significado que a mulher } \\
\text { atribui à perda da mama, principalmente } \\
\text { no que diz respeito à vida sexual. }\end{array}$ & $\begin{array}{l}\text { Oito mulheres no pós-operatório de } \\
\text { mastectomia. Clínica Cirúrgica e Gi- } \\
\text { necológica do Hospital Universitário } \\
\text { de Juiz de Fora-MG. }\end{array}$ \\
\hline $\begin{array}{l}\text { Tallhaferro, } \\
\text { Lemos, } \\
\text { Oliveira }^{20}\end{array}$ & $\begin{array}{l}\text { Estudo qualitativo, } \\
\text { descritivo-explora- } \\
\text { tório - nível VI }\end{array}$ & $\begin{array}{l}\text { Identificar os problemas enfrentados pela } \\
\text { mulher mastectomizada no seu contexto } \\
\text { de vida. }\end{array}$ & $\begin{array}{l}10 \text { mulheres com câncer de mama/ } \\
\text { mastectomizadas, com parceiros } \\
\text { fixos, que fazem acompanhamento } \\
\text { no ambulatório do Hospital de Base } \\
\text { (São José Rio Preto). }\end{array}$ \\
\hline
\end{tabular}

Os estudos buscaram conhecer os problemas enfrentados pela mulher mastectomizada, no seu contexto de vida, e a influência da mastectomia no desempenho de papéis, identificando as alterações ocorridas, assim como mecanismos de enfrentamento e rede de apoio. Alguns foram mais direcionados à percepção da sexualidade, buscando compreender o significado da mama na vida sexual e como as mulheres percebem o corpo após o procedimento. O estudo que abordou os parceiros buscou identificar o tipo de suporte oferecido e como eles percebem esse apoio.

Os temas abordados, nos artigos analisados, foram agrupados e subdivididos nas categorias temáticas: Conceito de sexualidade; Suporte do parceiro; e Alterações da sexualidade decorrentes do câncer de mama. O quadro 3 mostra a síntese do conhecimento, de acordo com as categorias. 
Quadro 3 - Síntese do conhecimento de acordo com as categorias temáticas: Conceito de sexualidade, Suporte do parceiro e Alterações da sexualidade decorrentes do câncer de mama

\begin{tabular}{|c|c|c|}
\hline & Estudo & Resultados/Conclusões \\
\hline \multirow{4}{*}{$\begin{array}{l}\text { Conceito de } \\
\text { sexualidade }\end{array}$} & $\begin{array}{l}\text { Rodrigues, } \\
\text { Silva, } \\
\text { Lopes }^{11}\end{array}$ & $\begin{array}{l}\text { Para grande parte das mulheres estudadas, o conceito de sexualidade se restringe } \\
\text { ao relacionamento sexual propriamente dito. } \\
\text { Algumas mulheres atribuíram esse conceito à imagem corporal. }\end{array}$ \\
\hline & $\begin{array}{l}\text { Souto, } \\
\text { Souza }^{13}\end{array}$ & $\begin{array}{l}\text { A sexualidade das mulheres aparece principalmente através da relação heterosse- } \\
\text { xual. } \\
\text { Também foi expressa pelo reconhecimento de sentimentos como amor, apoio e } \\
\text { preocupação demonstrados pelos parceiros. }\end{array}$ \\
\hline & $\begin{array}{l}\text { Tallhaferro, } \\
\text { Lemos, } \\
\text { Oliveira }{ }^{20}\end{array}$ & $\begin{array}{l}\text { A sexualidade aparece como servir sexualmente o parceiro e também associada ao } \\
\text { companheirismo, envolvendo o lado mais afetivo. }\end{array}$ \\
\hline & $\begin{array}{l}\text { Madeira, } \\
\text { Almeida, } \\
\text { Jesus }^{19}\end{array}$ & $\begin{array}{l}\text { As modificações na imagem corporal levam a uma rejeição de si mesma e afeta a } \\
\text { relação com o outro. } \\
\text { Sexualidade reduzida à mama. }\end{array}$ \\
\hline \multirow{7}{*}{$\begin{array}{l}\text { Suporte do } \\
\text { parceiro }\end{array}$} & $\begin{array}{l}\text { Rodrigues, } \\
\text { Silva, } \\
\text { Lopes }^{11}\end{array}$ & $\begin{array}{l}\text { Fica evidente a importância, atribuída pelas mulheres, na participação do marido } \\
\text { em todas as fases da doença, proporcionando o compartilhar afetivo das emoções, } \\
\text { dúvidas e preocupações. } \\
\text { O medo do afastamento do parceiro, da indiferença e do abandono leva a um dese- } \\
\text { quilíbrio pessoal. }\end{array}$ \\
\hline & $\begin{array}{l}\text { Souto, } \\
\text { Souza }{ }^{13} \\
\end{array}$ & $\begin{array}{l}\text { Importância do afeto e atenção do companheiro (satisfação em estar em sua compa- } \\
\text { nhia; impressão de que ela tem menos problemas). }\end{array}$ \\
\hline & $\begin{array}{l}\text { Tallhaferro, } \\
\text { Lemos, } \\
\text { Oliveira }\end{array}$ & $\begin{array}{l}\text { Evidente a importância do apoio do parceiro de forma integral para a recuperação da } \\
\text { mulher. A maioria dos parceiros dá o apoio necessário para a sua companheira. } \\
\text { O cônjuge tem um papel fundamental, durante todas as fases do tratamento, sendo } \\
\text { igualmente imprescindível a interação entre paciente e seu companheiro, durante a } \\
\text { reestruturação de sua integridade. }\end{array}$ \\
\hline & $\begin{array}{l}\text { Madeira, } \\
\text { Almeida, } \\
\text { Jesus }^{19}\end{array}$ & $\begin{array}{l}\text { Aparece o medo de perder o parceiro. } \\
\text { Possibilidade de continuar com uma relação sexual gratificante na companhia do } \\
\text { parceiro, quando ele sabe lidar com a nova situação. } \\
\text { O apoio do parceiro parece deixar a mulher mais segura. } \\
\text { Não ter parceiro pode significar ausência de cobranças no tocante à sexualidade. }\end{array}$ \\
\hline & $\begin{array}{l}\text { Barbosa, } \\
\text { Ximenes, } \\
\text { Pinheiro }^{15}\end{array}$ & $\begin{array}{l}\text { A participação e a iniciativa do marido constituem fortes determinantes na qualidade } \\
\text { do relacionamento conjugal. } \\
\text { A mulher tem necessidade de afeto. }\end{array}$ \\
\hline & $\begin{array}{l}\text { Gonçalves, } \\
\text { Arrais, } \\
\text { Fernandes }\end{array}$ & $\begin{array}{l}\text { A mastectomia culmina em dois tipos de comportamentos dos parceiros: dedicação } \\
\text { e apoio e falta de companheirismo. } \\
\text { O apoio e a dedicação dão forças para que a mulher busque melhores condições de } \\
\text { vida. Já a falta de companheirismo desestimula a busca de mecanismos de enfren- } \\
\text { tamento. } \\
\text { Ainda em relação ao parceiro, as mulheres experimentam o medo da rejeição e } \\
\text { temem o abandono. }\end{array}$ \\
\hline & $\begin{array}{l}\text { Biffi, } \\
\text { Mamede }\end{array}$ & $\begin{array}{l}\text { O suporte social oferecido pelos parceiros significou demonstração de afeto, com- } \\
\text { preensão da situação vivenciada por suas esposas, mesmo que de forma silenciosa. } \\
\text { Esse suporte funciona como incentivo às estratégias de autocuidado e colaboração } \\
\text { nas atividades domésticas. }\end{array}$ \\
\hline \multirow{2}{*}{$\begin{array}{l}\text { Alterações da } \\
\text { sexualidade } \\
\text { decorrentes } \\
\text { do câncer de } \\
\text { mama }\end{array}$} & $\begin{array}{l}\text { Rodrigues, } \\
\text { Silva }{ }^{11}\end{array}$ & $\begin{array}{l}\text { A mastectomia e os outros tratamentos contribuem para a diminuição da libido, mu- } \\
\text { danças na imagem corporal, na percepção do próprio corpo e no autoconceito. } \\
\text { A mulher apresenta ausência de desejo sexual. }\end{array}$ \\
\hline & $\begin{array}{l}\text { Tallhaferro, } \\
\text { Lemos, } \\
\text { Oliveira }{ }^{20}\end{array}$ & $\begin{array}{l}\text { O relacionamento sexual do casal fica comprometido pelo estresse emocional, dor, } \\
\text { fadiga, alterações na imagem corporal e autoimagem. } \\
\text { Entretanto, alguns relatos mostram que a mastectomia não alterou a vida sexual da } \\
\text { mulher. }\end{array}$ \\
\hline
\end{tabular}




\begin{tabular}{|c|c|c|}
\hline & Estudo & Resultados/Conclusões \\
\hline \multirow{6}{*}{$\begin{array}{l}\text { Alterações da } \\
\text { sexualidade } \\
\text { decorrentes } \\
\text { do câncer de } \\
\text { mama }\end{array}$} & $\begin{array}{l}\text { Biffi, } \\
\text { Mamede }^{14}\end{array}$ & $\begin{array}{l}\text { O distanciamento do casal, repercutindo diretamente no relacionamento sexual, tam- } \\
\text { bém foi expresso pelos parceiros como dificuldades enfrentadas após a mastectomia } \\
\text { de suas parceiras. } \\
\text { Alguns parceiros ficam nervosos quando ocorre abstinência sexual. }\end{array}$ \\
\hline & $\begin{array}{l}\text { Caetano, } \\
\text { Soares }{ }^{16}\end{array}$ & $\begin{array}{l}\text { Mudanças na percepção e desvalorização do próprio corpo. } \\
\text { A retirada da mama tem reflexos no relacionamento marital. } \\
\text { Interromperam ou mudaram suas atividades sexuais (estresse, ansiedade ou de- } \\
\text { pressão). }\end{array}$ \\
\hline & $\begin{array}{l}\text { Barbosa, } \\
\text { Ximenes, } \\
\text { Pinheiro } 15\end{array}$ & $\begin{array}{l}\text { Vivenciam mudanças na sexualidade após a mastectomia. } \\
\text { A perda da mama é encarada como ameaçadora à sua sexualidade, e o tratamento } \\
\text { cirúrgico traz consigo sentimentos de rejeição e de não aceitação da condição. } \\
\text { A mulher sente tristeza e preocupação com sua relação conjugal. }\end{array}$ \\
\hline & $\begin{array}{l}\text { Azevedo, } \\
\text { Lopes }{ }^{17}\end{array}$ & $\begin{array}{l}\text { A doença é marcada por mutilação, dor, perda do desejo sexual, impotência e rejei- } \\
\text { ção. } \\
\text { A mutilação do corpo tem reflexos na vida sexual (dificuldades nas relações interpes- } \\
\text { soais). } \\
\text { O órgão extirpado tem uma função primordial na relação entre a mulher e seus } \\
\text { objetos de desejo. }\end{array}$ \\
\hline & $\begin{array}{l}\text { Gonçalves, } \\
\text { Arrais, } \\
\text { Fernandes }^{18}\end{array}$ & $\begin{array}{l}\text { As mulheres mastectomizadas se sentem incapazes de dar prazer aos seus parcei- } \\
\text { ros. } \\
\text { Essa insatisfação com o corpo influencia na qualidade do relacionamento conjugal. } \\
\text { Ela sente vergonha de se despir, de ser tocada pelo companheiro, comprometendo } \\
\text { a relação sexual. }\end{array}$ \\
\hline & $\begin{array}{l}\text { Ferreira, } \\
\text { Franco, } \\
\text { Queiroz }^{12}\end{array}$ & $\begin{array}{l}\text { Após a mutilação, a mulher leva tempo para assimilar e incorporar a nova imagem } \\
\text { (sentimentos negativos como tristeza, estranheza e preocupação). } \\
\text { A vergonha do marido afeta a vida sexual, e o relacionamento conjugal é comprome- } \\
\text { tido pela evitação. }\end{array}$ \\
\hline
\end{tabular}

\section{DISCUSSÃO}

Os estudos analisados nesta revisão evidenciam que a maioria das mulheres tem uma visão da sexualidade centrada nos órgãos genitais e no relacionamento sexual. O conceito e o significado que elas atribuem à sexualidade são expressos em grande parte por um conceito reduzido ao ato sexual em si, ${ }^{11}$ ou mesmo reduzido ao seio. ${ }^{19}$ Quando são questionadas em como se sentem sexualmente após a mastectomia, as mulheres expressam uma sexualidade que para ser vivida necessita do outro, uma vez que as respostas trazem sempre a figura do parceiro. ${ }^{13} \mathrm{~A}$ falta de apropriação do próprio corpo ou mesmo a descrença na capacidade de obter prazer sozinha parecem levar as mulheres a colocarem a sua sexualidade "na mão do outro". ${ }^{21}$

Alguns relatos trazem a associação da sexualidade com imagem corporal, ${ }_{11}^{11}$ sendo manifestada por sentimentos como amor, apoio e preocupação demonstrados pelo parceiro. ${ }^{13}$ Nessa perspectiva mais ampliada, a sexualidade também engloba, além do sexo, o companheirismo, o amor, a aceitação e a felicidade. ${ }^{20}$

Nota-se, também, um conceito de sexualidade atrelado à dominação de gênero. ${ }^{20} \mathrm{~A}$ sexualidade desvincula-se totalmente de uma expressão natural do ser humano e passa a ser vivida como uma obrigação social onde não existem escolhas. Não obstante toda a dificuldade que a mulher esteja enfrentando em decorrência do câncer de mama, ela não pode esquecer o seu papel social enquanto esposa que, entre outras funções, implica servir sexualmente seu companheiro. Essa questão relaciona-se com as concepções da sexualidade feminina na sociedade. A mulher não possui autonomia na vivência da sua sexualidade e diante disso apresenta dificuldade em assumir para o companheiro a sua indisposição para o ato. ${ }^{22}$

Esse posicionamento assumido pelas mulheres denota que o controle masculino sobre a sexualidade da mulher ainda vigora, persistindo as assimetrias de gênero. ${ }^{21}$ Essa pressão social tende a dificultar a retomada da atividade sexual pela mulher que tem a necessidade básica de intimidade, o qual inclui mutualismo, respeito e comunicação.

A presença de um físico perfeito aparece como uma condição social e cultural para que se tenha um desempenho sexual satisfatório. Consequentemente, a ausência parcial ou total da mama implica um comprometimento da sexualidade. A perda da mama é muito significativa e gera muita dificuldade de aceitação pela própria mulher que demonstra sentimentos de insatisfação, ao perceber seu corpo alterado. ${ }^{20}$ É necessário um 
grande esforço para aceitar a atual condição, pois o "vazio" ocasionado pela ausência da mama transcende o corpo físico. ${ }^{19}$

O constrangimento torna-se ainda maior pela incerteza de como essa nova imagem será recebida pelo parceiro. ${ }^{19}$ As mulheres evitam a exposição e, em alguns casos, acreditam não mais servir para seus companheiros, ${ }^{13}$ temendo, inclusive, ser abandonadas por eles. As mamas representam a feminilidade, e a sua ausência pode significar interrupção da vida amorosa. Sem elas, as mulheres sentem-se excluídas da sociedade e rejeitadas sexualmente. ${ }^{19}$

O apoio do companheiro parece influenciar muito na vivência da sexualidade da mulher com câncer de mama e foi percebido como muito significativo, em todas as etapas da doença. Nos estudos analisados, as mulheres falam de uma sexualidade que para ser vivida necessita do outro e, consequentemente, se vêem ameaçadas quando o outro sinaliza falta de compreensão e ameaça abandoná-la diante das circunstâncias.

Quando ela conta com a compreensão e dedicação do parceiro, sente-se mais segura e consegue lidar melhor com a situação. ${ }^{19}$ Desfrutar da companhia significa carinho e atenção. ${ }^{13}$ Quando o companheiro consegue olhar para a região operada e aceita a nova imagem da mulher, é como se extinguisse o risco de abandono, tão temido. ${ }^{20}$

Por outro lado, a indiferença e o temor de ser rejeitada e abandonada agravam ainda mais a auto-organização e a reestruturação. A falta de compreensão do parceiro significa fracasso no enfrentamento. A opinião e a posição do parceiro são tão significativas que, quando a mulher não possui parceiro, ela se sente aliviada pelo fato de não ser cobrada e de não ter de dar satisfação. ${ }^{19}$

As mulheres acometidas pelo câncer de mama apresentam um comprometimento no exercício da sexualidade, em decorrência da mutilação e alterações na imagem corporal, dor, fadiga, mal-estar após a quimioterapia, perda do desejo sexual, estresse emocional e pelo medo de agravar a atual condição.

Muitas vezes as mulheres sentem-se constrangidas e com vergonha do companheiro e evitam a relação sexual já que, expor sua deformidade é algo considerado doloroso..$^{12}$ Com essa visão de distanciamento dos parceiros que, às vezes, é equivocada, as mulheres incorporam um sentimento de que há desinteresse e repulsa dos mesmos e acabam se afastando emocional e sexualmente. O desejo sexual pode ser afetado pela insatisfa- ção com o próprio corpo e pela não aceitação da perda da mama. É como se as alterações fossem limitantes para o exercício da sexualidade. ${ }^{15,17,20}$ Inicialmente existem outras preocupações que visam à recuperação, e a sexualidade volta a ser vivida ou mesmo sentida após algum tempo. ${ }^{13}$

A análise dos estudos evidencia uma assistência que não contempla esse aspecto do cuidado, necessitando de uma reestruturação da assistência prestada ${ }^{19} \mathrm{~A}$ enfermagem pode contribuir na promoção da saúde sexual, ${ }^{15}$ iniciando a abordagem da sexualidade da mulher com câncer de mama. Para isso torna-se necessário quebrar preconceitos ${ }^{13}$ e transpor barreiras culturais que impedem uma comunicação aberta e clara sobre sexualidade e problemas sexuais. Os profissionais de saúde precisam sensibilizar-se pela necessidade de ajustamento psicossocial dessas mulheres. ${ }^{20}$ Uma formação adequada também é preeminente, para que os enfermeiros possam prestar um cuidado holístico, com detecção precoce e prevenção de problemas sexuais. ${ }^{23}$

A sexualidade não é um conceito que pode ser considerado separado da saúde, consistindo num fator central para a manutenção do bem-estar e do autoconceito. ${ }^{24}$ Portanto, precisa ser incorporada nas discussões e fazer parte do cuidado, evitando que os pacientes fiquem repletos de preocupações, sentindo-se sozinhos e desamparados.

\section{CONSIDERAÇÕES FINAIS}

O diagnóstico e os tratamentos para o câncer de mama afetam a sexualidade da mulher, tanto na dimensão física quanto emocional. Muitas mulheres precisam de auxílio para superar o trauma da doença e do tratamento e para retomar a prática da sexualidade, de forma plena.

Torna-se imprescindível a elaboração de um plano de cuidados para essa mulher, com atuação direta nas questões de sexualidade. Essa assistência deve ser estendida aos parceiros que precisam ser estimulados a estarem mais próximos da mulher e a participarem de todo o processo, uma vez observada a importância de tal apoio. A enfermagem precisa reconhecer no parceiro sexual um suporte e trabalhar as dificuldades encontradas por eles, ao lidarem com a doença das suas parceiras, tornando-os elementos de apoio durante a reabilitação.

Essa reestruturação da assistência prestada exige um cuidado que ultrapasse a dimensão biológica e compreenda a mulher em todos os aspectos. Requer a presença de uma equipe multiprofissional. 
Os estudos sobre a sexualidade de mulheres com câncer de mama são geralmente descritivos, sendo escassos estudos que retratem evidências fortes, ou seja, estudos sobre intervenções ou mesmo de avaliação. Pelo número reduzido de artigos encontrados, tendo como autor dos estudos o profissional enfermeiro, evidencia-se a falta de produção científica nacional sobre a temática.

\section{REFERÊNCIAS}

1. Venâncio JL. Importância da atuação do psicólogo no tratamento de mulheres com câncer de mama. Rev Bras Cancerol. 2004 Jan-Mar; 50(1):55-63.

2. Jemal A, Siegel R, Ward E, Hao Y, Xu J, Murray T, et al. Cancer statistics, 2008. CA Cancer J Clin. 2008 Mar-Apr; 58(2):71-96.

3. Duarte TP, Andrade AN. Enfrentando a mastectomia: análise dos relatos de mulheres mastectomizadas sobre questões ligadas à sexualidade. Estud Psicol. 2003 Jan-Abr; 8(1):155-63.

4. Sheppard LA, Ely S. Breast cancer and sexuality. Breast J. 2008 Mar-Apr; 14(2):176-81.

5. Rogers M, Kristjanson LK. The impact on sexual functioning of chemotherapy induced menopause in women with breast cancer. Cancer Nurs. 2002 Feb; 25(1):57-65.

6. Hautamäki K, Miettinem M, Kellokumpu-Lehtinen PL, Aalto P, Lehto J. Opening communication with cancer patients about sexuality related issues. Cancer Nurs. 2007 Sept-Oct; 30(5):399-404.

7. Ressel LB, Gualda DMR. A sexualidade invisível ou oculta na enfermagem? Rev Esc de Enferm USP. 2002 Mar; 36(1):75-9.

8. Barton-Burke M, Gustason CJ. Sexuality in women with cancer. Nurs Clin North Am. 2007 Dec; 42(4):531-54.

9. Ursi, ES. Prevenção de lesões de pele no perioperatório: revisão integrativa da literatura [dissertação]. Ribeirão Preto (SP): Universidade de São Paulo, Escola de Enfermagem de Ribeirão Preto; 2005.

10. Zhang Y, Wildemuth BM. Qualitative analysis of content. In: Wildemuth BM, editor. Applications of social research methods to questions in information and library science. Westport: Libraries Unlimited; 2009 [acesso 2010 Out 10]. Disponível em: http:/ / www.ils.unc.edu/ yanz/Content_analysis.pdf

11. Rodrigues DP, Silva RM, Lopes MVO. A sexualidade da mulher mastectomizada: adaptando conceitos de Roy. Rev Enferm UERJ. 2000 Jan-Jun; 8(1):22-7.

12. Ferreira MLSM, Franco CB, Queiroz FC. Construindo o significado da mastectomia: experiência de mulheres no pós-operatório Rev Ciênc Méd (Campinas). 2002 Jan-Abr; 11(1):47-54.

13. Souto MD, Souza IEO. Sexualidade da mulher após a mastectomia. Esc Anna Nery Rev Enferm. 2004 Dez; 8(3):402-10.

14. Biffi RG, Mamede MV. Suporte social na reabilitação da mulher mastectomizada: o papel do parceiro sexual. Rev Esc Enferm USP. 2004 Set; 38(3):262-9.

15. Barbosa RCM, Ximenes LB, Pinheiro AKB. Mulher mastectomizada: desempenho de papéis e redes sociais de apoio. Acta Paul Enferm. 2004 Jan-Mar; 17(1):18-24.

16. Caetano JA, Soares E. Mulheres mastectomizadas diante do processo de adaptação do self-físico e self-pessoal. Rev Enferm UERJ. 2005 Maio-Ago; 13(2):210-6.

17. Azevedo RF, Lopes RLM. Vivência do diagnóstico de câncer de mama e de mastectomia radical: percepção do corpo feminino a partir da fenomenologia. Online Braz J Nurs. 2006 Abr [acesso 2010 Out 10]; 5(1). Disponível em: http://www.objnursing.uff.br/ index.php/nursing/article/view/137

18. Gonçalves SROS, Arrais FMA, Fernandes AFC. As implicações da mastectomia no cotidiano de um grupo de mulheres. RENE Rev Min Enferm. 2007 Mai-Jun; 8(2):9-17.

19. Madeira AMF, Almeida GBS, Jesus MCP. Refletindo sobre a sexualidade da mulher mastectomizada. REME Rev Min Enferm. 2007 Jul-Set; 11(3):254-7.

20. Talhaferro B, Lemos SS, Oliveira E. Mastectomia e suas conseqüências na vida da mulher. Arq Ciênc Saúde. 2007 Jan-Mar; 14(1):17-22.

21. Garcia ORZ. Sexualidades femininas e prazer sexual: uma abordagem de gênero [tese]. Florianópolis (SC): Universidade Federal de Santa Catarina, Programa de Pós-Graduação Interdisciplinar em Ciências Humanas; 2007.

22. Trindade WR, Ferreira MA. Sexualidade feminina: questões do cotidiano das mulheres. Texto Contexto Enferm. 2008 Set; 17(3):417-26.

23. Akinci AC. The comfort levels of nurses during clinical experiences which include sexual topics. Sex Disabil. 2011 Sep; 29(3):239-50.

24. Shepard LA, Ely S. Breast cancer and sexuality. Breast J. 2008 Mar-Apr; 14(2):176-81. 